\title{
METHODOLOGICAL APPROACHES TO VETERINARY SERVICE EFFICIENCY EVALUATION IN LIVESTOCK
}

\author{
Natalia Bannikova', Anzhelika Baicherova ${ }^{2}$
}

\begin{abstract}
Summary
This paper presents the contradiction between modern views on the role of veterinary science from the concept "one health" position, which implies an important role in health assurance and the welfare of the whole veterinary care society, and existing methodological support of its efficiency evaluation. The analysis of existing methods of veterinary attendance efficiency evaluation was conducted on the case of Stavropol Territory and with the help of canonical correlations method their disadvantages were shown. The paper provides rationalization for the need of veterinary science external effect consideration, which operates in healthcare and environmental protection. The procedure for calculating the integral coefficient of veterinary service efficiency was proposed, which allows taking into account the complex of internal and external effects.

The integral coefficient may be used in the process of comparative analysis, in the specification of strategic growth priorities, in the motivation system integration of veterinary service employees.
\end{abstract}

Key words: efficiency, evaluation, veterinary service.

JEL: $Q 57, P 21$

\section{Introduction}

Animal diseases constitute serious threat not only to the livestock industry, but for health and well-being of society as a whole. That is why the necessity of integrated approaches for the definition of animals' veterinary care role, functions and organization as evidencebased as from the point of view of further development directions is actively discussed by researchers from different countries. Based on Dr. Calvin Schwabe's vision of „one medicine“" researchers consider the role of veterinary science in protecting food security and safety, prevention and control of antroponotic diseases, removing a threat of antibiotic

1 Natalia Bannikova, Ph.D., Doctor of Economics, Professor, Stavropol State Agrarian University, Faculty of Economics, 12 Zootekhnicheskiy by-street, 355017 Stavropol, Russian Federation, Phone: +7 86523574 66/ext. 1231, E-mail: nbannikova@mail.ru

2 Anzhelika Baicherova, Ph.D., Senior lecturer, Stavropol State Agrarian University, Faculty of Economics, 12 Zootekhnicheskiy by-street, 355017 Stavropol, Russian Federation, Phone: +7 86523574 66/ext. 1230, E-mail: corsta@mail.ru

EP 2014 (61) 4 (959-974) 
sensitivity, environmental and ecosystem protection, readiness to bioterrorism threat, and also to the appearance of new agents emerge to threaten human and animal populations (Pappaioanou, 2004; Sargeant, 2008; Steele, 2008; Davis, 2008). Gradually the concept "one medicine" should be transformed into the concept "one health", and on a global scale, considering developing ecosystem approaches and strengthening globalization processes (Zinsstag et al., 2011).

However, the withdrawal from traditional views on the role and functions of veterinary science is related to a number of problems. In particular, the approaches to veterinary services evaluation are required to be developed, including economic efficiency. Methods of efficiency evaluation of certain veterinary measures or animals' specific diseases prevention and treatment systems are sufficiently developed and widely used in research and practice. To provide a rationale for the choice of more efficient means of animal protection, different methods are used, from survey and expected damage calculation to economic and mathematical models construction (for example, Reist et al., 2012; Boklund et al., 2013; Murai et al., 2014). Nevertheless, the evaluation of veterinary services efficiency as infrastructural subsystem of territorial agrarian system, and also socio-economic system as a whole, didn’t get adequate substantiation.

This issue is particularly important for developing countries and countries with transitional economies, in many of which the institutional and organizational reform of the veterinary service takes place (Amankwah et al., 2014; Rutabanzibwa, 2011; Rich and Perry, 2011; Nikitin and Sabiryanov, 2012). Depending on how the results of veterinary service will be evaluated, the directions and rate of its further reforms will be determined, including its role in health providing and well-being in the society.

\section{Materials and Methods}

The analysis of existing methods of veterinary services efficiency evaluation was conducted on the case of Stavropol Territory, which is among the most advanced in terms of agricultural production regions in Russia. Data for the present study purposes are from reports of Stavropol Territory Veterinary Department.

For the regional veterinary service efficiency evaluation, the existing methods were used. The first one was developed by I. N. Nikitin, which is stated by Veterinary Department of Ministry of Agriculture of the Russian Federation and specified in textbooks, being in use to train specialists in veterinary science (Nikitin and Apalkin, 2007). According to this method for economic efficiency specification of preventive, therapeutic and remedial measures, focused on diseases prevention, animal mortality and loss of livestock production, the following indicators system should be used: economic damage by loss of livestock production, economic damage by animal mortality, alienation, compulsory extermination, compulsory animal slaughter, economic damage by breeding value decrease, economic damage by product quality decrease, economic damage by animal yield reduction, economic damage by screening of affected carcasses, organs, materials and animal products withdrawals; economic damage, which was stopped by preventive measures and diseases 
liquidation; economic effect, generated in preventive, therapeutic and remedial measures; saving of material and operational maintenance; economic efficiency of veterinary services; pay-back period of additional investments to equipment for veterinary services; labour efficiency of veterinary physicians.

The second method was developed by R. V. Miroshnichenko and it is based on I. N. Nikitin's approach. Its main dissimilarity is aggregation of effect sums from veterinary services conducted and their reconciliation with costs of medical and preventive activities costs of veterinary service support (Miroshnichenko, 2005). Thus, the present method gives an opportunity for integrated index calculation, which allows us to give generalized results evaluation of veterinary services activities. However, the disadvantage of any integrated index is the inequality of certain factors, which form it, influence. For the research of these factors influence, the method of canonical correlation was used and its algorithm was set out in relevant publications (Thorndike, 2000).

For the specification of brucellosis disease incidence as one of the serious diseases, which is general for people and animals, the data from Federal Hygiene and Epidemiology Centre of Federal Service for Oversight of Consumer Protection and Welfare were applied.

\section{Results}

More than 20 years ago there was a shift from complete government control to market relations in Russia, nevertheless, velocity, sequence, depth and results of the reforms in different industries have considerable discrepancy. But particular problems in the liberalization process are observed in industries related with infrastructure and they are still entirely or partially in the area of government control. The demand for that is connected with economic reasons (natural monopoly, for example, in electrical energy industry), and also with the necessity of public interests protection) population and animal protection from epidemics.

That is why the state has still a key value in veterinary services organization in Russia. Entrepreneurship in the sphere of veterinary service sufficiently developed in cities and towns, but in rural localities, the owners of small farms and farm livestock don't always aware the importance of veterinary activities (especially preventive ones) and have opportunity to pay for them. Thus with the view of veterinary well-being adherence at the territories and small agricultural producers support, every region has its own advanced state veterinary service.

For Stavropol Territory livestock is structure-forming and some of the most socially important branch of agriculture. The share of animal products in total volume of agricultural products in 2013 was $30.8 \%$. Stavropol Territory livestock is rank second in sheep population and wool production, ninth in poultry population, and tenth in cow population and milk production in the Russian Federation.

State Veterinary Service of Stavropol Territory provides services for this livestock population and consists of Veterinary Department, Stavropol territory station for animal 
diseases control, 26 district and 5 town state veterinary institutions with total number more than 1,200 employees. Besides, more than 330 veterinary specialists work in large agricultural enterprises.

The condition of veterinary well-being in the region is traditionally evaluated with the help of indicators, which reflects data on diseases and animal mortality. During the last 4 years, annual animal mortality in Stavropol Territory was from 2.8 to 4 thousand in animal units of cattle and from 3.6 to 33.6 thousand in animal units of sheep, which is not more than $1.6 \%$ with regard to available animal population. The situation is still complicated in pig breeding in Stavropol Territory. It is connected with long-term persisting threat of African swine fever flare. However, the measures taken to control the conditions of pigs and prevent the threat of the spread of African swine fever, led to the fact that during the last two years flares of this disease were not observed.

As shown in Figure 1, the major share of animal diseases is accounted for noncommunicable diseases. The most common among them are diseases of the reproductive organs of cattle, diseases of the digestive organs of pigs, and breathing system of sheep and pigs.

Figure 1. Dynamics of livestock diseases in Stavropol Territory

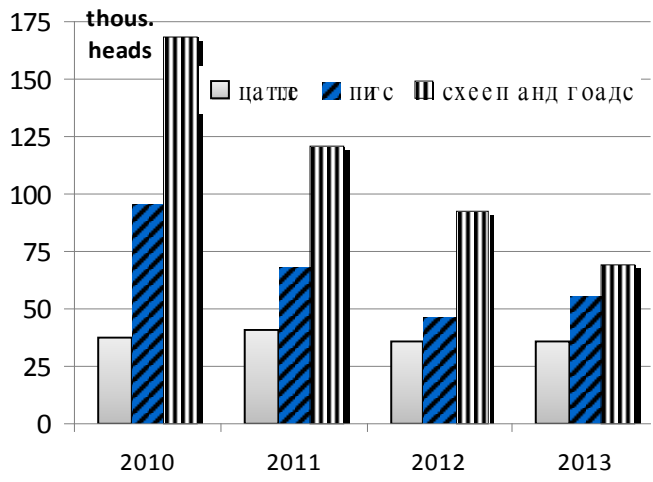

a) non-communicable diseases

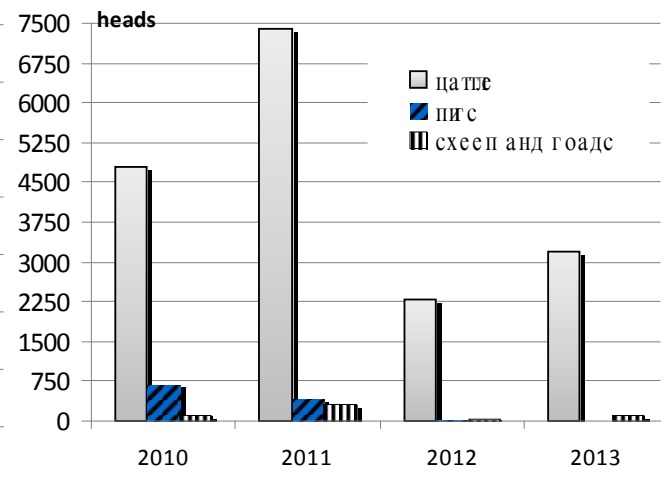

b) infectious diseases

Source: Livestock and poultry population. Livestock production, 2014.

Diagnostic and research activities aimed to prevent threat of mortality and the spread of dangerous diseases play an important role to maintain veterinary well-being. Based on the results of diagnostic studies the most important manipulation is conducted; they are aimed to maintain the epizootic welfare - vaccination and veterinary treatment for farm animals. During the study period, the number had increased. For example, the number of vaccinations and veterinary treatment of cattle on the main types of diseases such as aphthous fever and Siberian plague increased by $12.5 \%$ and $17.0 \%$, respectively. According to Stavropol Territory veterinary service data, the total value of veterinary services in 2013 was 633.3 million. Efficient and focused work of veterinary specialists of Stavropol Territory became the reason that in recent years, in the region there were 
no recorded cases of such especially dangerous diseases as Siberian plague, aphthous fever, classical swine fever. Thus, we can conclude that in general, in Stavropol Territory the veterinary situation is prosperous; there are low rates of morbidity and mortality of livestock, which in recent years have tended to decline.

As is known, veterinary service costs in livestock constitute a significant share and should be justified due to improved production results or reduction of losses. Therefore the evaluation of economic efficiency is essential as for certain activities as for veterinary service in general.

To evaluate the efficiency of Stavropol Territory veterinary service the method proposed by R. V. Miroshnichenko (2005) was used. The calculation results are presented in Table 1.

Table 1. The calculation of economic efficiency of Stavropol Territory veterinary service functioning

\begin{tabular}{|l|r|r|r|r|}
\hline \multicolumn{1}{|c|}{ Indicator } & \multicolumn{1}{c|}{$\mathbf{2 0 1 0}$} & \multicolumn{1}{c|}{$\mathbf{2 0 1 1}$} & \multicolumn{1}{c|}{$\mathbf{2 0 1 2}$} & \multicolumn{1}{c|}{$\mathbf{2 0 1 3}$} \\
\hline Prevented damage by animal diseases, million RUB & $2,370.5$ & $2,943.4$ & $2,205.4$ & 232.1 \\
\hline Actual damage by animal diseases, million RUB & $1,009.2$ & 836.6 & 816.1 & 745.9 \\
\hline $\begin{array}{l}\text { Additional value obtained by increasing the number and } \\
\text { improving the quality of products, million RUB }\end{array}$ & 315.0 & 351.0 & 392.0 & 411.6 \\
\hline $\begin{array}{l}\text { Economy of material and labour costs as a result of more } \\
\text { efficient tools and methods usage for veterinary service, } \\
\text { million RUB }\end{array}$ & 6.5 & 5.4 & 1.1 & 1.6 \\
\hline $\begin{array}{l}\text { Costs of preventive, therapeutic and remedial measures, } \\
\text { million RUB }\end{array}$ & 130.2 & 146.4 & 332.1 & 323.9 \\
\hline Costs of veterinary service support, million RUB & 517.0 & 587.5 & 424.7 & 579.7 \\
\hline $\begin{array}{l}\text { Indicators of regional veterinary service functioning } \\
\text { economic efficiency }\end{array}$ & 1.6 & 2.4 & 1.4 & 1.2 \\
\hline
\end{tabular}

Source: Author's development based on data from Stavropol Territory Veterinary Department, 2010-2013.

According to Table 1 there is the dynamics of economic efficiency indicator reduction that can be explained by the increase in anticipating costs of preventive, remedial and therapeutic measures. Thus, it appears that the positive trend to reduce morbidity, growth in livestock production as key indicators of veterinary service activities, do not have the expected effect on its performance evaluation. Positive results are distorted because of the influence of external inflationary factors beyond the control of the veterinary infrastructure functioning.

This is primarily indicative of used method imperfection. To consider more details of separate elements influence and the results of calculations and make more objective conclusions, the dependence of Stavropol Territory veterinary service efficiency on a number of key factors was investigated.

As an instrumentality basis the method of canonical correlation was used, intended to establish the nature of the link between the set of the determinants and the resultant variables. The main advantage of the canonical correlation method is the possibility of 
establishing correlation connection between the two groups of factors, not limited by the necessity of multi-collinearity of indicators exceptions. Furthermore, in terms of a small amount of the original statistical data, the method allows not to restrict significantly the possible range of the variables used (Thorndike, 2000).

As the variables, indicators, that according to the existing method of veterinary service performance evaluation were crucial, were used. These include: the group $\mathrm{x}_{1}-\mathrm{x}_{4}$, which characterizes the effect, and the group $\mathrm{x}_{5}-\mathrm{x}_{6}$, which characterizes the embedded component.

$\mathrm{x}_{1}$ - prevented damage by animal diseases, which reflects the economy of agricultural producers costs from avoided mortality and loss free conditions of animal products; $\mathrm{x}_{2}$ - actual damage by animal diseases, which reflects the actual size of losses from mortality, compulsory slaughter and culling, as a result of animal diseases. The difference between prevented and actual damage, which can be determined when the efficiency index is calculated. The efficiency index represents the economic efficiency which is obtained from the prevention of animal diseases spread;

$\mathrm{x}_{3}$ - additional value, received due to increasing the number of quality and quantity of animal products in consequence of medical and preventive activities;

$\mathrm{x}_{4}$ - economy of financial and labour due to application of more efficient means and methods of veterinary measures, which shows the level usage of new, efficient means of zoonosis" prevention;

$\mathrm{x}_{5}$ - costs for preventive, diagnostic and treatment measures, which have the form complex of means for preventing animals diseases;

$\mathrm{x}_{6}-$ costs for management of veterinary service.

Actual values of mentioned earlier variables which characterized activity's efficiency of veterinary service in Stavropol Territory for 8 years since 2006 till 2013 were used as basic data for conducting of canonical analysis.

The results of calculation have shown, that canonical correlation index is statistically significant as its constancy in different variations has characterized index fixity which characterizes the results of veterinary service in different changes.

Closeness of relationship between canonical variables is characterized by value of canonical correlation index which is 0.996 . It means strong correlation between actual variables and resulting indicators which was received after linear combination conducting.

Canonical variables with canonical index of correlation $r_{1}=0,996$ for actual set of variables (here and after they are with standardized value) have the form:

$$
\begin{aligned}
& V_{1}=0,367_{x_{1}}+0,405_{x_{2}}-1,010_{x_{3}}+0,015_{x_{4}} \\
& U_{1}=-0,897_{x_{5}}-0,849_{x_{6}}
\end{aligned}
$$


Indexes in the formulas of canonical variables reflect the power of impact of actual variables on the meaning of another canonical variable. Following the algorithm of calculation, on each stage one or several less significant factors should be rejected and then conduct the calculation again till the maximum indexes of actual and shorted variables' composition won't be differed significantly. That is why variable $\mathrm{x}_{4}$ was rejected for the next step as it gives the less contribution to $V_{1}$. Besides economy of financial and labour costs as a result of application of more efficient measures and methods do not have significant meaning in calculation of veterinary service management efficiency. Its quantitative meaning testify the lack of new and more efficient measures and methods of preventive, diagnostic and treatment measures whereby economic effect got after their implementation does not play significant role in management efficiency of veterinary service.

In the next step of calculations, the following canonical indexes were received:

$$
\begin{aligned}
& V_{2}=0,343_{x_{1}}+0,395_{x_{2}}-0,998_{x_{3}}, \\
& U_{2}=-0,884_{x_{5}}-0,274_{x_{6}}
\end{aligned}
$$

It should be mentioned that canonical indexes with remained variables have been changed insignificantly in $\mathrm{V}_{2}$, and correlation in $\mathrm{U}_{2}$ has been changed noticeably. This has reflects the fact that the change of variables, reflecting the effect of veterinary service activity, influences much more on costs of diagnostic and treatment measures conducting then on costs of veterinary service management.

Statistically significant canonical index of correlation has remained unchangeable $(0,996)$ that is evidence of the least meaning of rejected variable and correctness of its reduction activities. Its value points out on almost linear dependence between canonical variables.

The results of calculations evidence that prevented $\left(\mathrm{x}_{1}\right)$ and actual damage $\left(\mathrm{x}_{2}\right)$ have significantly less impact on indicator of efficiency of veterinary service in comparison with additional value received due to increasing the quantity and quality of service $\left(\mathrm{x}_{3}\right)$. The significance of cost driver in veterinary service is also high $\left(\mathrm{x}_{5}\right)$. Such a results could be explained by the fact that the significant amount of additional value, received due to increasing of quantity and quality of service is identified by the situation which is in the animal breading now and also by trends of growth of prices for animal products

At the same time, the influence of the additional cost of the action is limited by to the typical agrarian sphere mechanism which is "price scissors", as the costs of veterinary preventive actions grow more intense. This relation leads to the result, according to which the performance indicator of veterinary service in recent years is reduced.

So, the disadvantage of the method is significant impact of inflation factors on the of economic efficiency indicators calculation results. Distorting influence primarily has the rising cost of preventive and curative measures, on which the veterinary service can not affect. 
Confirmation of this fact is the data in Table 2, which reflects the dynamics of the prices of some veterinary drugs, the most heavily used in modern veterinary care. Rise in price of raw materials for the production of some vaccines, steady demand from the veterinary services, the lack of direct competition for some types of goods in the market of veterinary bio industry contribute to the annual increase in costs for the vaccination of cattle, which directly affects the cost of animal products.

Table 2. Changes in prices for the most popular veterinary products

\begin{tabular}{|c|c|c|c|c|c|}
\hline \multirow[b]{2}{*}{ Name of vaccine } & \multicolumn{4}{|c|}{ Price per unit, RUB } & \multirow{2}{*}{$\begin{array}{l}\text { Variation } \\
(2013 \text { to } \\
2010, \text { in \%, } \\
(+,-), \text { p.p. })\end{array}$} \\
\hline & 2010 & 2011 & 2012 & 2013 & \\
\hline $\begin{array}{l}\text { A vaccine against brucellosis in } \\
\text { farm animals from strain } 19\end{array}$ & $3,583.7$ & $3,583.7$ & $3,583.7$ & $3,642.9$ & 101.7 \\
\hline $\begin{array}{l}\text { FMD vaccine culture mono- and } \\
\text { multivalent inactivated adsorbed }\end{array}$ & $16,300.3$ & $16,926.5$ & $17,015.2$ & $19,926.5$ & 122.3 \\
\hline $\begin{array}{l}\text { Virus vaccine against classical } \\
\text { swine fever from strain LK- } \\
\text { VNIIVV and M culture dry }\end{array}$ & 423.5 & 443.0 & 680.2 & 703.8 & 166.2 \\
\hline $\begin{array}{l}\text { A set of components for the } \\
\text { diagnosis of brucellosis in animals } \\
\text { RA, and RSK, RDSK }\end{array}$ & 543.9 & 557.5 & 564.1 & 575.5 & 105.8 \\
\hline $\begin{array}{l}\text { Set for the serological diagnosis of } \\
\text { bovine leukaemia }\end{array}$ & $5,004.8$ & $6,255.9$ & $6,120.5$ & $6,255.9$ & 125.0 \\
\hline $\begin{array}{l}\text { Test system for detection of ASF } \\
\text { virus DNA by PCR }\end{array}$ & $6,540.0$ & $7,845.0$ & $7,890.1$ & $7,925.0$ & 121.2 \\
\hline
\end{tabular}

Source: Annual reports of Stavropol Territory Veterinary Department, 2010-2013.

As for the costs of veterinary services, the opposite dynamics are observed, namely a decrease of $17.8 \%$. This situation can be explained by the shortage of budgetary funds, as well as staff reductions of veterinary service during ongoing reform.

Thus, a significant increase in the cost of treatment and preventive measures, and a slight reduction in the cost of the veterinary service of the region resulted in a noticeable increase in costly component in the computation of the efficiency of the veterinary service. This situation, in our opinion, determines the need for further improvement of the methodology for evaluating the performance of veterinary services.

\section{Discussion}

Based on the conception "one health" in evaluating the effectiveness of the veterinary service should consider not only the results obtained in the livestock industry, but also the effects that occur in the field of public welfare. In this matter it is advisable to use the approach of V. V. Kafidov (2012), according to which one should distinguish between the internal and external efficiency of infrastructure sectors. 
External efficiency means creating the infrastructure of economic benefits for society. For veterinary infrastructure, these benefits will be resulted in saving money at the elimination of foci of particularly dangerous animal diseases, reducing the incidence of zoonotic diseases and, as a consequence, reduce costs, not directly related to the object of veterinary care - cattle. It may be costs associated with disabilities sick people, as well as environmental damage.

Under the external efficiency implies creating the infrastructure of economic benefits for society. For veterinary infrastructure, these benefits will be reduced to save money at the elimination of foci of particularly dangerous animal diseases, reducing the incidence of zoonotic diseases and, as a consequence, costs reduction, not directly related to the object of veterinary care - cattle breeding. It could be costs associated with disable sick people, as well as environmental damage.

Internal efficiency is expressed in achieving their goals of a particular infrastructure sector. In this case, the internal efficiency of the veterinary infrastructure reflects the rational use of material, labour and financial resources, the use of appropriate methods and tools to address issues related to safeguard animal health.

To assess the internal efficiency of the veterinary service is advisable to use the formula underlying the methodology proposed I. N. Nikitin:

$$
E_{t}=\frac{P_{d}+C_{a}+S_{c}-C_{v}}{C_{v}}
$$

where, $\mathrm{E}_{\mathrm{t}}$ - economic efficiency of veterinary measures ("health-related efficiency"); $\mathrm{P}_{d}$ - economic damage prevented as a result of veterinary measures, RUB;

$\mathrm{C}_{a}$ - value received additionally by increasing the number and improving the quality of products, RUB;

$\mathrm{S}_{c}$ - saving labour and material costs as a result of more effective tools and methods for veterinary measures, RUB;

$\mathrm{C}_{v}$ - the costs of veterinary measures, RUB (Nikitin and Apalkin, 2007).

However, in integrated assessment of internal efficiency of the veterinary service it is not sufficient to use only the parameters characterizing the damage prevented and the costs of the relevant activities. These cost parameters, as already demonstrated above, to a certain extent distort the results of Veterinary Service. Therefore, it is advisable to assess the internal efficiency to form a system of indicators to include additional assessment indicators.

Firstly, in terms of the reform of the state veterinary service, accompanied by a reduction of personnel, it is appropriate to assess the impact of professional level of specialists, i.e. efficient use of the veterinary service of its human resources. For this, by comparing the actual amount of work performed by veterinary per employee and the appropriate standard ratio is proposed to estimate the level of intensity of veterinary specialists. This indicator is a summary nature, as aggregated for complex therapeutic measures provided veterinary service. 


$$
C_{\text {s.in.lab }}=\sum_{i=1}^{n} \lambda_{i} \frac{\left(A_{w} / N_{e}\right)_{\text {fact }_{i}}}{\left(A_{w} / N_{e}\right)_{\text {norm }_{i}}}
$$

where, $\mathrm{C}_{\text {s.in.lab }}$ - consolidated ratio of the intensity of labour veterinary experts;

$\mathrm{A}_{w}$-volume of completed veterinary specialists work;

$\mathrm{N}_{e}$ - number of employees, people.;

$\lambda_{i}$ - weight index reflecting the relative importance of the work performed and defined by experts, $\lambda_{i}>0, i=1, \ldots, n, \sum_{i=1}^{n} \lambda_{i}=1$.

Secondly, the level of veterinary welfare in a particular territory reflects the level of morbidity and mortality rate of animals. These indicators are also advisable to take into account in the evaluation of internal efficiency.

Thus, comprehensive evaluation allows us to give the integral index of internal efficiency of the veterinary services, taking into account the cost-effectiveness of therapeutic and preventive measures, the labour intensity of veterinary specialists, as well as the current level of morbidity and mortality of livestock. For this the following formula is advisable:

$$
C_{\text {int }}=E_{t} \times C_{\text {s.in.lab }} \times \frac{1}{L_{\text {morb }}} \times \frac{1}{L_{\text {mort }}}
$$

where, $\mathrm{C}_{\text {int }}$ - the integral index of internal efficiency;

$\mathrm{L}_{\text {morb }}$ - incidence of animals;

$\mathrm{L}_{\text {mort }}$ - level of animals' mortality.

To evaluate the external effectiveness of veterinary service it is needed revealing the effects of veterinary activity, manifested in such areas as health and environmental protection.

Modern veterinary practice involves a series of activities leading to pollution, depletion and deterioration of land. One of the inevitable consequences of the implementation of veterinary measures is the collection, recycling and disposal of biological waste which is a biological material obtained as a result of clinical work and the elimination of foci of animal diseases. Special danger is infected animal carcasses, which should be eliminated in specially designated and equipped burial grounds. Consequently, the burial of infected animals is the cause of environmental pollution. The problem of biological waste disposal and destruction is relevant not only for Russia (McLean et al., 2007).

In addition, the negative impact on the environment can render a treatment of livestock conducted regularly by veterinary service they are disinfection and disinfestations, which also contribute to the deterioration of land as a result of exposure to chemical disinfectants and formulations. 
Obviously, the damage to the environment due to veterinary measures should be evaluated. The method approved by Order of the Ministry of Natural Resources 08.07.2010, № 238. (Method of calculating the amount of harm caused by soil as object of protection of the environment) can be used.

Calculation of the value of damage as a result of disposal of production and consumption is carried out by formula:

$$
D_{w}=\sum_{i=1}^{n}\left(M_{i} \times T_{w} \times S\right) \times C_{s}
$$

where, $\mathrm{D}_{w}$ - amount of damage as a result of disposal of production and consumption (RUB);

$\mathrm{M}_{i}$ - weight of waste with the same hazard class (ton);

$n$ - number of waste types, grouped by hazard classes within an area that has the waste disposal;

$\mathrm{T}_{w}$ - fee for calculating the amount harm caused to soil as environmental objects when soil degradation as a result of unauthorized waste disposal (RUB/ton);

$S$ - polluted site area $\left(\mathrm{m}^{2}\right)$;

$\mathrm{C}_{s}$ - index, depending on the category of land and purpose of land on which there is a contaminated area, agricultural land 1.6.

Calculation of the value form in the amount of damage by chemical pollution of soil is carried out by the formula:

$$
D_{c}=L_{c} \times S \times C_{d} \times C_{s} \times T_{c}
$$

where, $\mathrm{D}_{c}$ - amount of damage in the chemical soil pollution (RUB);

$\mathrm{L}_{c}$ - degree of chemical pollution during treatment, disinfection, etc. is assumed equal to 1.5 ;

$S$ - polluted site area $\left(\mathrm{m}^{2}\right)$;

$\mathrm{C}_{d}$ - index depending on the depth of chemical contamination or damage to the soil;

$\mathrm{C}_{s}$ - index, depending on the category of land and the target;

$\mathrm{T}_{c}$ - fee for calculation of the harm amount caused to soil as environmental objects in the chemical soil pollution $\left(\mathrm{RUB} / \mathrm{m}^{2}\right)$.

Total damage caused to the environment is determined by adding the two selected types of damage:

$$
D_{e}=D_{w}+D_{c}
$$

where $\mathrm{D}_{e}$ - overall damage to the environment due to veterinary activities, rub.

To determine the index of efficiency of veterinary activities manifested in the field of environmental protection, the economic damage caused by the veterinary service of the environment should be considered. In this case, the economic damage to the 
environment is considered as a negative result, and high costs to prevent the spread of animal diseases as compared to the damage as positive one. Consequently, in the case of exceeding the costs of pollution prevention over the damage, the result of performance of veterinary services can be considered effective.

$$
E_{e p}=1 / \frac{D_{e n v}}{C_{v . n}}
$$

where, $\mathrm{E}_{e p}$ - effectiveness of veterinary measures, manifested in the field of environmental protection; $\mathrm{D}_{e n v}$ - economic damage caused to the environment in the process of veterinary measures, RUB;

$\mathrm{C}_{v \cdot n .}$ - costs of veterinary services on prevention of environmental pollution, RUB.

The important role of veterinary measures effectiveness is in preservation of life and health of people. Is known, there are a lot of infections and parasitic animal diseases common to humans and animals. Man is infected by them in contact with sick animals, as a result of eating the meat of sick animals, contaminated water and through blood-sucking insects and mites. The role of the veterinary service in healthcare is to minimize the health and social consequences of these diseases by monitoring and immunization of animals in order to prevent human infection.

The most widespread and dangerous diseases common to humans and animals are: Siberian plague, rabies, brucellosis, rabbit disease, ornithosis or psittacosis, toxoplasmosis, fascioliasis, leptospirosis, flesh worm disease, echinococcosis, tuberculosis, aphtha, salmonellosis and others.

One of the most widespread diseases which are common to humans and animals is brucellosis. The problem of protecting people and animals from the disease continues to be relevant for many countries (Mainar Jaime and Vázquez Boland, 1999; Marcotty et al., 2013).

Brucellosis is classified as occupational disease, as the majority of patients are infected during labour activity. Currently morbidity statistics in Russia by types of activities is as follows: 35.9\% - animal keepers, 30.5\% - veterinarians and paramedics (Overview of the epidemiology of brucellosis in the Russian Federation, 2014). Brucellosis is extremely dangerous and socially significant infection, bringing significant economic damage and cause a high level of patients' disability - 18.3\%. In regions with high morbidity rate this figure exceeds $52 \%$. According to preliminary data of the World Health Organization in the Russian Federation, there are about 3.0 thousand patients with brucellosis. The annual cost of prevention, treatment and maintenance of people with brucellosis, according to experts of WHO is about 63 million RUB. Minimization of morbidity cases of brucellosis and other antroponotic animal diseases depends on the veterinary service efficiency.

To determine the veterinary service efficiency, which is manifested in healthcare, use the following formula is suggested to use: 


$$
E_{h}=1 / \frac{D_{h p}}{C_{v . h}}
$$

where, $\mathrm{E}_{h}$ - veterinary activities efficiency, is manifested in healthcare sphere; $\mathrm{C}_{v, h}$ - veterinary services costs to prevent antroponotic animal diseases, RUB; $\mathrm{D}_{h p}$ - economic damage, caused to the health of people, rub., the value of which is calculated by the following formula:

$$
D_{h p}=\sum_{n} X_{c} \times C_{t} \times C_{o d} \times C_{d . s .}
$$

where, $\mathrm{X}_{c}$ - number of diseased, people;

$\mathrm{C}_{t}$ - treatment costs per patient, RUB;

$\mathrm{C}_{d . s .}$ - disease severity index (is determined by experts on the basis of the characteristics of a disease);

$n$ - the number of diseases considered in the calculation.

For integrated evaluation of veterinary service efficiency, taking into account both external and internal effects, it is appropriate to calculate the integrated index of veterinary well-being provision efficiency in territories:

$$
C_{i}=w \times C_{\text {int }}+(1-w) \times C_{\text {ext }}
$$

where, $\mathrm{C}_{i}$ - integrated index of veterinary service economic efficiency;

$w$ - weight index, reflecting the degree of importance of the internal effect in the results of the veterinary service. Weight index $w$ is determined by expertise, based on the conditions of a territory. Thus, for Stavropol Territory, according to experts of Stavropol regional station for animal diseases control, this figure should be 0.85 .

Thus, the proposed integrated index allows us to give generalized evaluation of the providing veterinary well-being efficiency and to compare the results of the individual structural units of the veterinary service. The analysis of this index components allow to justify key objectives in the field of veterinary services in particular territories, taking into account the effect of external and internal activities.

\section{Conclusions}

Existing approaches to the veterinary service efficiency evaluation, as a rule, are focused on complex assessment of veterinary activities and take into account the results, which can appear only in livestock. In addition, the evaluation results are influenced by characteristic for agrarian sector effect of "price scissors", due to the advanced growth for veterinary medicines and materials prices, compared with the prices of animal products. To eliminate these disadvantages, the existing methodological support should be upgraded. 
The efficiency of veterinary infrastructure broadly defined should be regarded as the indicator of veterinary well-being success of a territory in terms of both internal and external effect. The internal effect is manifested in the results of therapeutic activities on reduction of farm animals' morbidity, and the external effect is reflected in the areas that are not directly the subject of veterinary services (healthcare, environmental protection).

Supposed integrated index allows us to reflect the external and internal effects holistically, with the help of which it is possible to make the comparison of the results of veterinary service activities in different regions. Comparative analysis of the integrated index components will clarify the strategic goals and identify current challenges of veterinary service in a particular area.

Further research into the practical application of the indicators included in the integrated index calculation, can be directed to the development of recommendations for the construction of Balanced Scorecard (BSC) on their basis, which will allow to motivate employees of veterinary service in achieving strategic goals.

\section{References}

1. Amankwah, K., Klerkx, L., Sakyi Dawson, O., Karbo, N., Oosting, S. J., Leeuwis, C., Zijpp, A. J. (2014): Institutional dimensions of veterinary services reforms: responses to structural adjustment in Northern Ghana, International Journal of Agricultural Sustainability, vol. 12, no. 3, pp. 296-315.

2. Boklund, A., Halasa, T., Christiansen, L. E., Enøe, C. (2013): Comparing control strategies against foot-and-mouth disease: Will vaccination be cost-effective in Denmark? Preventive Veterinary Medicine, vol. 111, no. 3-4, pp. 206-219.

3. Davis, D. K. (2008): Brutes, beasts and empire: veterinary medicine and environmental policy in French North Africa and British India, Journal of Historical Geography, vol. 34, no. 2, pp. 242-267.

4. Federal Hygiene and Epidemiology Centre (2014): Overview of the epidemiology of brucellosis in the Russian Federation, Federal Service on Surveillance for Consumer rights protection and human well-being - Federal Hygiene and Epidemiology Centre, available at: http://rospotrebnadzor.ru/upload/iblock/609/o-napravlenii-obzora-obepid.situatsii-po-brutsellezu-v-rossiyskoy-federatsii-v-razdely-epidnadzor-i-pisma.pdf

5. Kafidov, V. V. (2012): Peculiarities of infrastructure efficiency evaluation, Management of economic systems, № 47, available at: www.uecs.ru/marketing/item/

6. Mainar Jaime, R. C., Vázquez Boland, J. A. (1999): Associations of veterinary services and farmer characteristics with the prevalence of brucellosis and border disease in small ruminants in Spain, Preventive Veterinary Medicine, vol. 40, no. 3-4, pp. 193-205.

7. Marcotty, T., Thys, E., Conrad, P., Godfroid, J., Craig, P., Zinsstag, J., Meheus, F., Boukary, A. R., Badé, M. A., Sahibi, H., Filali, H., Hendrickx, S., Pissang, C., Herp, M. van., Roost, D. van der, Thys, S., Hendrickx, D., Claes, M., Demeulenaere, T., Mierlo, 
J. van, Dehoux, J. P., Boelaert, M. (2013): Intersectoral collaboration between the medical and veterinary professions in low-resource societies: The role of research and training institutions, Comparative Immunology, Microbiology and Infectious Diseases, vol. 36, no. 3, pp. 233-239.

8. McLean, M., Watson, H. K., Muswema, A. (2007): Veterinary waste disposal: Practice and policy in Durban, South Africa (2001-2003), Waste Management, vol. 27, no. 7, pp. 902-911.

9. Ministry of Nature (2010): Methods of calculating the harm amount, caused by soil as object of environmental protection, Order № 238, Ministry of Nature, Moscow, Russian Federation, available at: http://base.consultant.ru/cons/cgi/online. cgi?req $=$ doc;base $=$ LAW;n $=164425$

10. Miroshnichenko, R. V. (2005): The organization of interaction between authorities and business organizations in the field of veterinary service: thesis, Ph.D. in Economics, thesis, Faculty of Economics, Stavropol State Agrarian University, Stavropol, Russian Federation.

11. Murai, K., Lehenbauer ,T. W., Champagne, J. D., Glenn, K., Aly, S. S. (2014): Costeffectiveness of diagnostic strategies using quantitative real-time PCR and bacterial culture to identify contagious mastitis cases in large dairy herds, Preventive Veterinary Medicine, vol. 113, no. 4, pp. 522-535.

12. Nikitin, I. N., Apalkin, V. A. (2007): Veterinary business organization and economics, KolosS, Moscow, Russian Federation.

13. Nikitin, I. N., Sabiryanov, A. F. (2012): The state task to veterinary establishments - new method of organization of activity of a veterinary service, Scientific Notes of the Kazan State Academy of Veterinary Medicine, № 211, pp. 430-434.

14. Pappaioanou, M. (2004): Veterinary medicine protecting and promoting the public's health and well-being, Preventive Veterinary Medicine, vol. 62, no. 3, pp. 153-163.

15. Reist, M. , Jemmi, T. , Stärk, K. D. C. (2012): Policy-driven development of costeffective, risk-based surveillance strategies, Preventive Veterinary Medicine, vol. 105, no. 3, pp. 176-184.

16. Rich, K. M., Perry, B. D. (2011): The economic and poverty impacts of animal diseases in developing countries: New roles, new demands for economics and epidemiology, Preventive Veterinary Medicine, vol. 101, no. 3-4, pp. 133-147.

17. Rutabanzibwa, A. P. (2011): Veterinary legal reform in Tanzania, In: Primary Animal Health Care in the $21^{\text {st }}$ Century: Shaping the Rules, Policies and Institutions Theme one: General Policy, Legislation and Institutional Issues, Ministry of Water and Livestock Development, The Republic of Tanzania, available at: http://sites.tufts.edu/capeipst/ files/2011/03/Rutabanzibwa-Mombasa.pdf

18. Sargeant, J. M. (2008): The influence of veterinary epidemiology on public health: Past, present and future, Preventive Veterinary Medicine, vol. 86, no. 3-4, pp. 250-259.

19. Stavropol Territory Veterinary Department, Annual reports (for certain years 2010-

EP 2014 (61) 4 (959-974) 
2013), Stavropol, Russian Federation.

20. Steele, J. H. (2008): Veterinary public health: Past success, new opportunities, Preventive Veterinary Medicine, vol. 86, no. 3-4, pp. 224-243.

21. Territorial authority of the Federal State Statistics Service of the Stavropol Region (2014): Livestock and poultry population - Livestock production, Stavropol, Russian Federation.

22. Thorndike, R. M. (2000): Canonical Correlation Analysis, in Book-Tinsley, H. E. A., Brown, S. D. (Eds.), Handbook of Applied Multivariate Statistics and Mathematical Modelling, ch. 9, pp. 237-263, Academic Press, San Diego, CA, USA.

23.Zinsstag, J., Schelling, E., Waltner Toews, D., Tanner, M. (2011): From "one medicine" to "one health" and systemic approaches to health and well-being, Preventive Veterinary Medicine, vol. 101, no. 3-4, pp. 148-156. 